\title{
Erratum to: QTL for yield and associated traits in the Seri/Babax population grown across several environments in Mexico, in the West Asia, North Africa, and South Asia regions
}

\author{
Marta S. Lopes • Matthew P. Reynolds • C. Lynne McIntyre • Ky L. Mathews • \\ M. R. Jalal Kamali • Moussa Mossad - Yousef Feltaous • Izzat S. A. Tahir • \\ Ravish Chatrath $\cdot$ Francis Ogbonnaya $\cdot$ Michael Baum
}

Published online: 16 April 2013

(C) Springer-Verlag Berlin Heidelberg 2013

Erratum to: Theor Appl Genet (2013) 126:971-984

DOI 10.1007/s00122-012-2030-4

Due to an unfortunate error, the data of the first five rows on the second page of Table 5 were published in the wrong column. The corrected Table 5 is reproduced on the following pages.

The online version of the original article can be found under doi:10.1007/s00122-012-2030-4.

M. S. Lopes $(\varangle) \cdot$ M. P. Reynolds - K. L. Mathews CIMMYT Int. Apdo., Postal 6-641, DF Mexico 06600, Mexico e-mail: m.dasilva@cgiar.org

C. L. McIntyre

CSIRO Plant Industry, Queensland Biosciences Precinct,

306 Carmody Rd, St Lucia, QLD 4067, Australia

M. R. Jalal Kamali

CIMMYT, c/o Seed and Plant Improvement Institute Campus (SPII), Mahdasht Avenue, P.O. Box 1119, Karaj 31585, Iran

M. Mossad · Y. Feltaous

Field Crops Research Institute, Agricultural Research Center,

9 El-Gamma Street, Giza 12619, Egypt

I. S. A. Tahir

ARC, P.O. Box 126, Wad Medani, Sudan

I. S. A. Tahir · F. Ogbonnaya · M. Baum

ICARDA, P.O. Box 5466, Aleppo, Syria

R. Chatrath

Directorate of Wheat Research (DWR), Karnal 132 001,

Haryana, India 


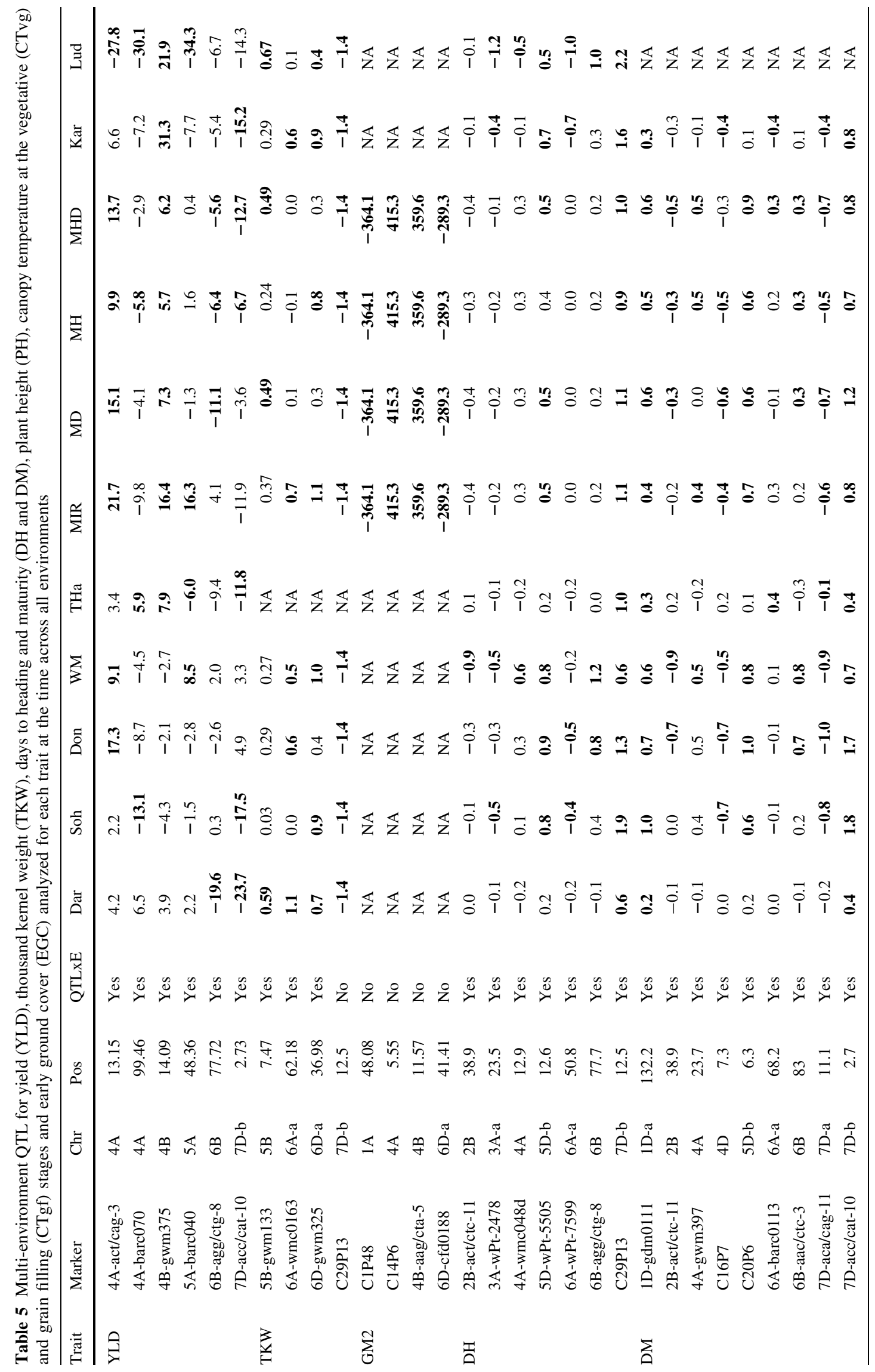




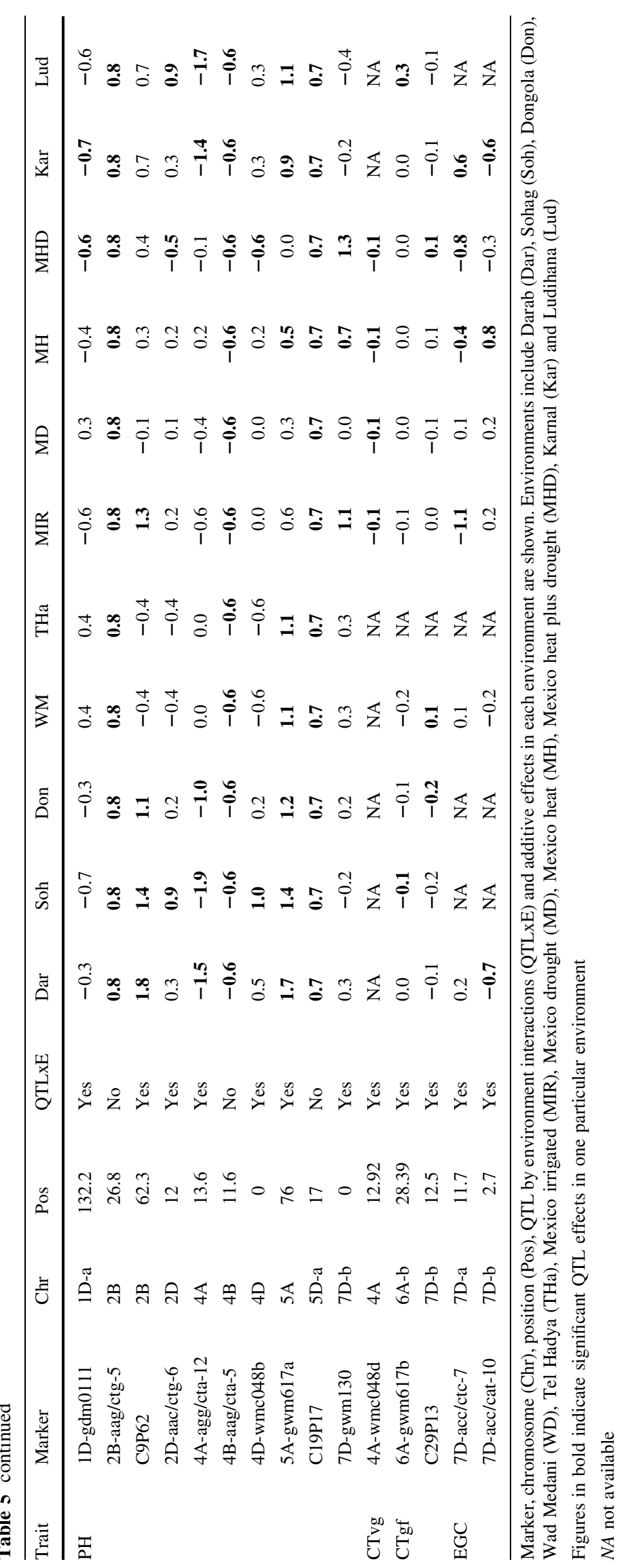

